\title{
واقع التربية الفنية لاعم الأطفال ذوي صعوبات التعلم في المدارس (المرحلة الابتائية) بالجهراء ومتطلباتها من وجهة نظر معلمي التربية الفنية
}

الاكتور/ فها عيادة فهاد الحربي استاذ مساعد كلية التربية الاساسية - قسم التربية الفنية

الملخص

هدف البحث إلى تعرف واقع التربية الفنية في دعم الأطفال ذوي صعوبات التعلم في المدارس (المرحلة الابتدائية) بالجهراء

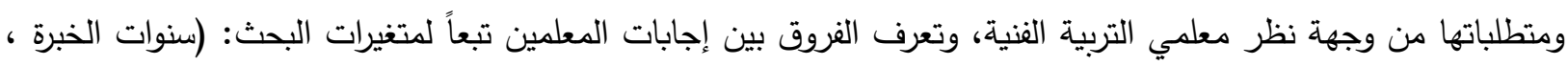

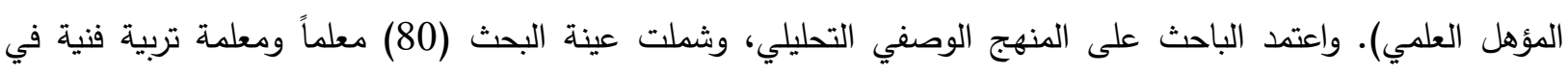
محافظة الجهراء، وقام الباحث ببناء أداة استبانة مكونة من (40) بنداً موزعة على بعلى بعدين، ومن أهم النتائج: - - بينت النتائج أن قيمة المتوسط للبعد الأول، وهو واقع التربية الفنية في دعم الأطفال ذوي صعوبات التعلم في المدارس (1.76)، وهي تقع ضمن التقدير المتوسط مما يدل على وجود حاجة لتطوير واقع التربية الفنية في دعم الأطفال ذوي صعوبات التعلم في المدارس. - - بينت النتائج أن قيمة المتوسط للبعد الثاني، وهو متطلبات التربية الفنية لدعم الأطفال ذوي صعوبات التعلم في المدارس

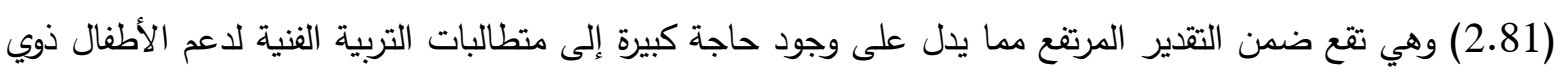
صعوبات التعلم في المدارس. - لا توجد فروق دالة إحصائياً بين متوسطات إجابات المعلمين على استبانة البحث تعزى إلى متغير المؤهل العلمي. - - ل الوجد فروق دالة إحصائياً بين متوسطات إجابات المعلمين على استبانة البحث تعزى إلى متغير سنوات الخبرة. • وتوصل البحث إلى عدد من المقترحات، ومن أهمها: - وضع خطة مشتركة بين جميع الأطراف في المدرسة بالتعاون مع الأهل لدعم الأطفال ذوي صعوبات التعلم. - - تضمين التربية الفنية بأهداف تراعي الأطفال ذوي صعوبات التعلم. - - وضع خطط فردية لمساعدة الأطفال ذوي صعوبات التعلم.

الكلمات المفتاحية: التربية الفنية، معلم التربية الفنية، صعوبات التعلم. 


\title{
The Situation of Art Education in Support of Children with Learning Disabilities in Schools (Primary Stage) in Jahra and the Requirements of its Development from the Point of View of Art Education Teachers
}

\begin{abstract}
The Objective of the research is to know the situation of art education in support of children with learning disabilities in schools (primary stage) in Jahra and the requirements of its development from the point of view of Art Education Teachers, and know the differences between the teacher answers depending on variables: (years of experience, qualification). The researcher adopted a descriptive analytical method, and the sample contained (80) members from Art Education Teachers in primary schools in Jahra so the researcher built his tools of questioner on (40) items distributed on tow dimension, and the most important results:

-The results showed that the average value of the first dimension, the situation of art education in support of children with learning disabilities in schools (1.77), falls within the average estimate, indicating the need to develop the situation of art education in support of children with learning disabilities in schools.

-The results showed that the average value of the second dimension, the requirements of art education to support children with learning disabilities in schools (2.81), falls within the high estimate indicating that there is a great need for technical education demands to support children with learning disabilities in schools.

-There are not significant differences between the averages responses teachers on the research questionnaire based on variable of Qualification for qualified individuals who possess less scientific.

-There are not significant differences between the averages responses teachers on the research questionnaire based on variable of years of experience.for the benefit of individuals who have fewer years of experience.

The research reached number of suggestions, these are some important ones:

- Develop a joint plan between all parties in the school in cooperation with parents to support children with learning disabilities.

- Include art education goals that take into account children with learning disabilities.

- Develop individual plans to help children with learning disabilities.
\end{abstract}

Keywords: Art Education, Teacher of Art Education, Learning Disabilities. 
تعد مشكلة صعوبات التعلم من المشكلات التي يواجهها المعلم في المدرسة، ويحتاج إلى أبرز استرتيجيات التعلم، وأساليب العلاج للتعامل مع تلك الصعوبات، والتخفيف من حدتها، وعلاجها إن أمكن.

ويُعد موضوع صعوبات التعلم من الموضوعات الحديثة نسبياً في ميدان التربية، وتعاني فئة صعوبات التعلم من تدني في

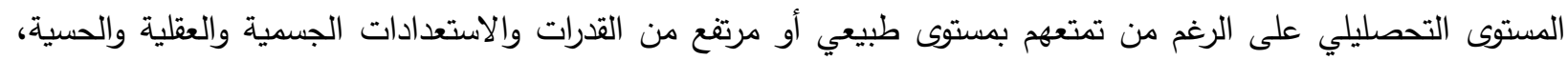

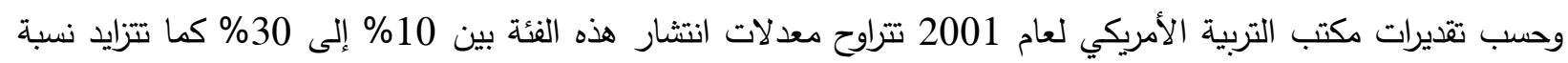

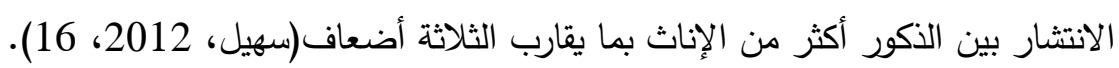

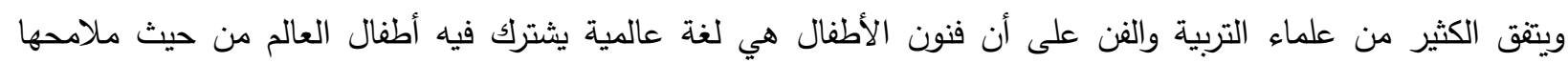

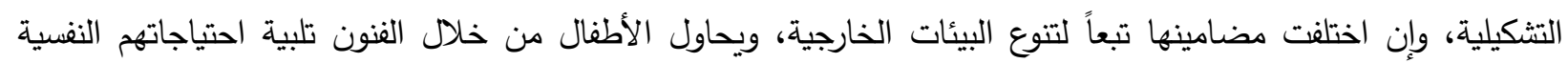

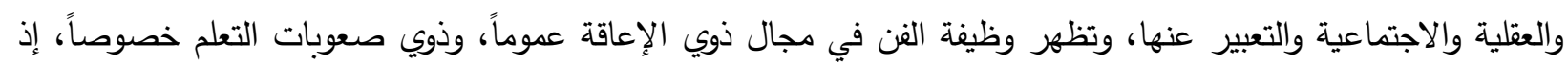
يتيح لهذه الفئة للتعبير عن احتياجاتهم وانفعالاتهم من خلال الفن، ويعزز الفن من قدراتهم ويتح لهم المجال أمام ابداعاتهم لكي لهي يصبحوا فاعلين ومنتجين في المجتمع كأقرانهم العاديين، وهذا ما يحقق لهم التكيف مع أقرانهم العاديين في المجتمع(الثقفي، ونئ .). 2017، وتهدف التربية الفنية إلى إيجاد إنسان يتذوق العمل الفني, ويقوم بعمليات الابتكار والإبداع للعمل الفني عند ممارسته للفن بأشكاله المتعددة وأساليبه المتتوعة، وبذلك تكون التربية الفنية نشاطاً ييسر للمتعلم الحرية في التنكير والتعبير , ويكتسب قيماً عالية (الخوالدة، الترتوري، 2006، 185). و ذكر سيوليتين" تعليم الفنون هو مجال استثنائي للنشاط مصدم لتعزيز شخصيات

$$
\text { أكثر إبداعاً وأكثر تعليماً" (سيوليتيين، 2002، 563، 5. }
$$

وقد أظهرت الدراسات أن برامج التربية الفنية قد ساعدت الطلاب على تحسين مستوى أدائهم في التحصيل الدراسي في المجالات الدراسية الأخرى ذلك أن النشاطات الفنية تزيد من فاعلية أداء النشاط النصف الكروي الأيمن للدماغ مما ينعكس إيجابياً على مهارات التفكير عند الطلاب". (Jensen, 2001.23), لذا يرى الباحث أن المشاركة في الأعمال الفنية الجماعية من خلال دروس التربية الفنية, يكون لها الأثر الفعال في تتمية مهارات المتعلمين الاجتماعية والثخصية والتعليمية. ومعلم التربية الفنية "يسعى إلى تتمية الثخصية ككل ويعمل على تكاملها عن طريق الفن فييسر للمتعلم البيئة المناسبة التي تمكنه من أن يفكر ويحس ويعي وينشط وينمو بعملياته العقلية والجسمية خلال المشكلات الفنية التي يعالجها. فمعلم التربية الفنية المبدع يعمل على التتمية الثاملة للمتعلم, من خلا الممارسة لتأكيد الذات واكتساب المهارات وتحسين الذوق" (إيمان، 2007، 84) والاستجابة لتطورات الحياة من حوله ولما يحدث في المجمع الإنسانى من تغيرات وما يستجد فيه من اتجاهات

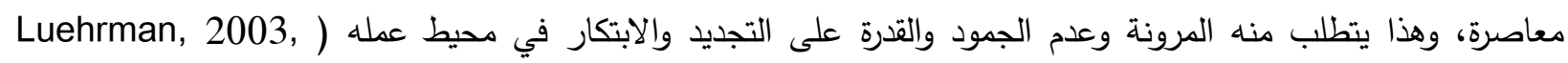

وتسهم التربية الفنية بما تحتويه من الأنثطة المختلفة من الرسم، والتشكيل بالطين، والمعجون، والورق، وغيرها في عملية بناء شخصية المتعلم، وتحفيز طاقات التلاميذ بما يلبي حاجاتهم ونموهم. 
وبناءً على ما تقدم تأتي أهمية التربية الفنية وتدريسها في دعم التلاميذ ذوي صعوبات التعلم، من خلال التأثير في شخصية الطفل خلال مرحل نموه المختلفة، وبناءً على ذلك سعى البحث الحالي إلى الوقوف على واقع التربية الفنية في دعم الأطفال

ذوي صعوبات التعلم ومتطلباتها

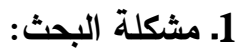

يعاني من مشكلة صعوبات التعلم الكثير من التلاميذ، إذ تؤثر صعوبات التعلم على مستوى تحصيلهم الدراسي فيكون مستواهم التحصيلي متدني على الرغم من تمتعهم بمستوى طبيعي أو مرتفع من القدرات والاستعدادات العقلية.

ويتقق معظم المتخصصين في مجال صعوبات التعلم على تقسيم صعوبات التعلم إلى نوعين هما: الصعوبات النمائية وتتعلق بنمو القدرات العقلية والعمليات المسؤولة عن التوافق الدراسي للتلميذ، وتوافقه الثخصي والاجتماعي وتثمل صعوبات (الانتباه

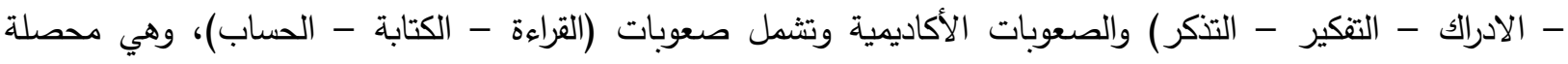

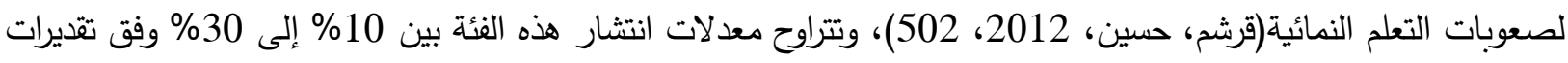
مكتب التربية الأمريكي لعام 2001، كما تتزايد نسبة الانتشار بين الذكور أكثر من الإناث بما يقارب الثثلاثة أضعاف (سهيل،

وتكمن خطورة مشكلة صعوبات التعلم في انتشارها لدى قطاع عريض من الأطفال الذين يتمتعون بمستوى عادي وقد يكون

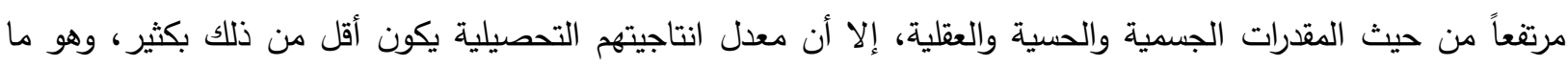

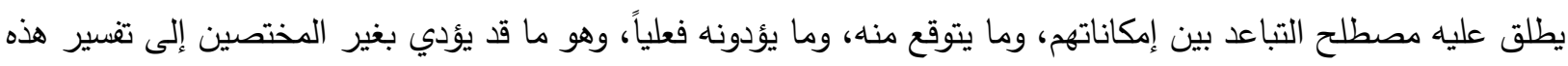

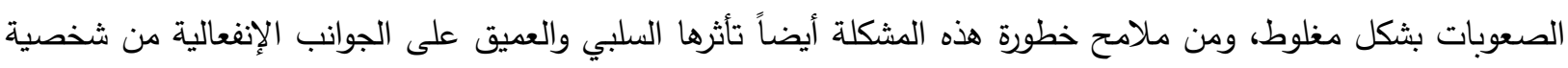
الطفل، ودافعيته نحو الدراسة، والتي تلعب دوراً كبيراً في أدائه المدرسي، وتحصيله الدراسي إذ يزداد مع اشتداد وطأتها شعور

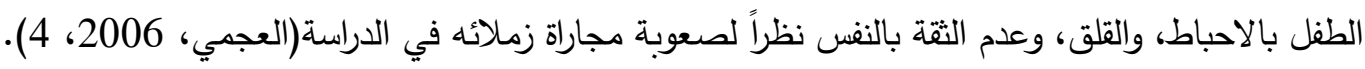

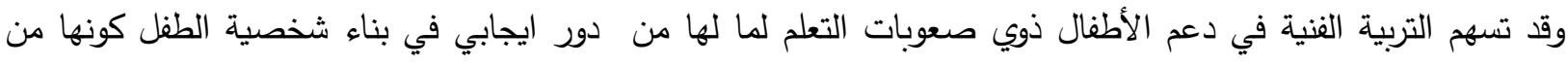
المواد الدراسية المحببة للأطفال، ومن أهم أهدافها تتمية شخصية الطفل خلاية دوعل مرحل نموه المختلفة, وذلك من خلال الأنشطة

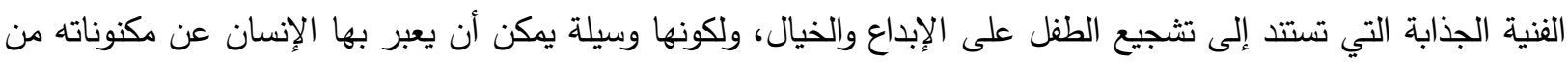
خلا إتاحة المجال للطفل للتعبير عن أفكاره بالرسم، والتشكيل بمختلف الطرائق.

وتسهم التربية الفنية بما تحتويه من أنشطة مختلفة تتضمن (الرسم والتثكيل بالطين والمعجون والورق وغيرها) في عملية بناء شخصية الطفل وتوجيه سلوكه. وتعمل الأنثطة الفنية كدافع للتعلم لما لها من أثر في التقليل من اتجاهات الطلاب السلبية نحو المدرسة وفي تتمية الاتجاه الايجابي نحوها (أيواي، 2002، وتعديه

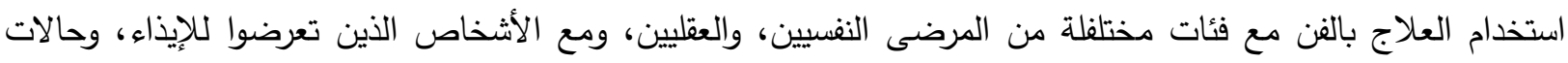

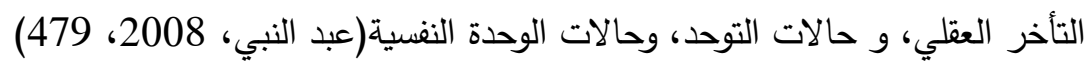
ومن خلال خبرة الباحث السابقة في ميدان التعليم وزياراته المتكررة للمدارس، وعمله الحالي كأستاذ في كلية التربية الأساسبة تبين له انتشار مشكلة صعوبات التعلم في المدارس، والحاجة لدعم التلاميذ الذين يعانون من تلك المشكلة من خلال

$$
\text { تظافر الجهود بين جميع الأطراف في المدرسة(المدير - المرشد - المعلم - أولياء الأمور) . }
$$

ولما لصعوبات التعلم من من آثار سلبية تتعكس على الجوانب الإنفعالية من شخصية الطفل، ودافعيته نحو الدراسة، والتي تلعب دوراً كبيراً في أدائه المدرسي، وتحصيله الدراسي إذ يزداد مع اشتداد وطأتها شعور الطفل بالاحباط، والقلق، وعدم الثقة بالنفس. 
كان لا بد من تعاون جميع الأطراف عموماً، والتربية الفنية خصوصاً ولدعم ذوي صعوبات التعلم والوقوف على متطلبات

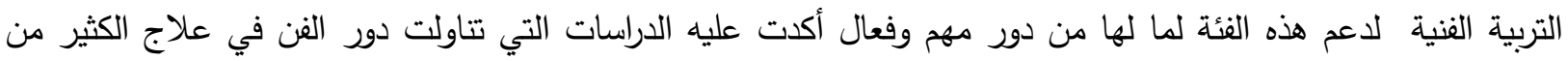
المشكلات التي تعاني منها فئات مختلفة ومنها فئات ذوي الإعاقة. ومما سبق يمكن تحديد مشكلة البحث في السؤال الآتي: ما واقع التربية الفنية لاعم الأطفال ذوي صعوبات التعلم في المدارس في المدارس (المرحلة الابتدائية) بالجهراء ومتطلباتها من وجهة نظر معلمي التربية الفنية؟

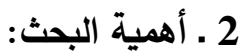
تأتي أهمية البحث من الآتي: 1) أهمية تعرف واقع التربية الفنية في دعم الأطفال ذوي صعوبات التعلم في المدارس الابتدائية. 2) أهمية تعرف متطلبات التربية الفنية لاعم الأطفال ذوي صعوبات التعلم في الددارس الابتدائية.

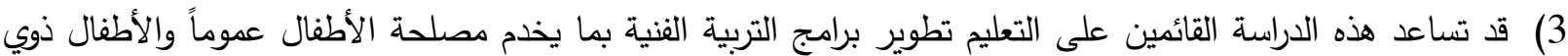
صعوبات التعلم خصوصاً. 4) قد تسهم الدراسة في زيادة الوعي بأهمية مشكلة الأطفال ذوي الإعاقة عموماً والأطفال ذوي صعوبات التعلم خصوصاً، وتجلياتها على المجتمع، وضرورة مساعدتهم وإدماجهم لممارسة دورهم الطبيعي في المجتمع. 3 ـ أهداف البحث: سعى البحث إلى تحقيق الأهداف الآتية: 1. تعرف واقع التربية الفنية في دعم الأطفال ذوي صعوبات التعلم في المدارس في المدارس الابتدائية في الجهراء من وجهة نظر معلمي التربية الفنية. 2. تعرف متطلبات التربية الفنية لدعم الأطفال ذوي صعوبات التعلم في الددارس في المدارس الابتدائية في الجهراء من وجهة نظر معلمي التربية الفنية.

3. تعرف الفروق بين إجابات المعلمين على استبانة البحث تبعاً لمتغيرات البحث: (سنوات الخبرة ، المؤهل العلمي). 4 1. ما واقع التربية الفنية في دعم الأطفال ذوي صعوبات التعلم في المدارس في المدارس الابتدائية في الجهراء من وجهة نظر معلمي التربية الفنية؟.

2. ما متطلبات التربية الفنية لدعم الأطفال ذوي صعوبات التعلم في المدارس في المدارس الابتدائية في الجهراء من وجهة نظر معلمي التربية الفنية؟. 3. هل توجد فروق بين إجابات المعلمين على استبانة البحث تبعاً لمتغيرات البحث: (سنوات الخبرة في التدري، المؤهل العلمي) ؟. (1) n

5 ـ فرضيات البحث: سيتم اختبار الفروض عند مستوى الدلالة (0.05): 1- لا توجد فروق ذات دالة إحصائية بين متوسطات إجابات المعلمين على استبانة البحث تعزى إلى متغير سنوات الخبرة في التدريس. 2- لا توجد فروق ذات دالة إحصائية بين متوسطات إجابات المعلمين على استبانة البحث تعزى إلى متغير المؤهل العلمي. 
1- الحدود البشرية: اقتصرت الدراسة على وجهة نظر معلمي التربية الفنية في مدارس المرحلة الابتدائية في محافظة

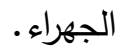

2- الحدود الزمنية: طبقت الدراسة في الفصل الدراسي الثاني من عام 2018/2017. 3- الحدود المكانية: مدارس المرحلة الابتدائية في محافظة الجهراء. 7 ـ مصطلحات البحث والتعريفات الإجرائية: • صعوبات التعلم: الأطفال ذوي صعوبات التعلم أولئك الأطفال الذين يظهرون اضطرابات في واحدة، أو أكثر من

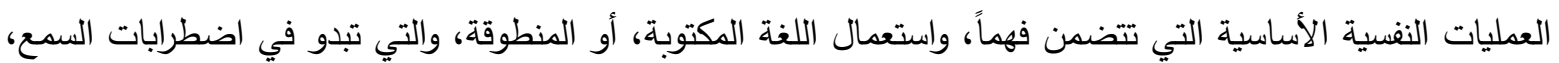
والتتكير، والكلام، والقراءة، والتهجئة، والحساب، والتي تعود لأسباب تتصل بخلل بسيط في وظائف الدماغ، ولكنها لا لانيان

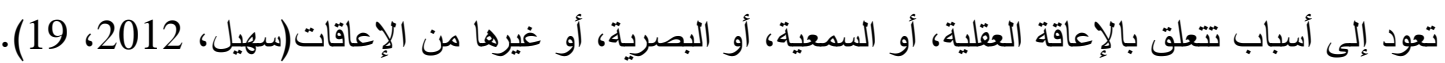
التربية الفنية: التربية الفنية هي تربية التلاميذ عن طريق ترقية نموهم الفني وتطوير مهاراتهم اليدوية الفنية، وتتمية

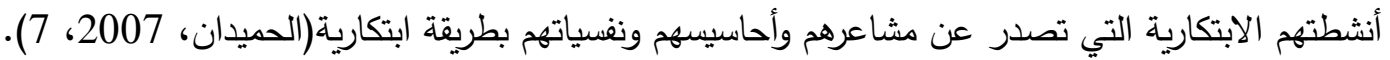
التربية الفنية في البحث: هي المادة التي تهدف إلى تتمية شخصية التلميذ بجميع مكوناتها من خلال منهج التربية الفنية

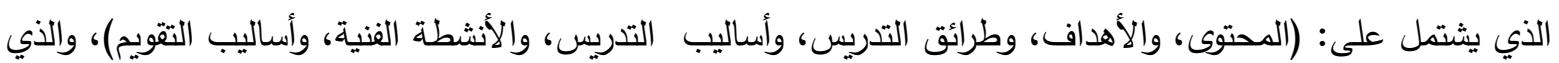
يتيح للتلميذ التعبير عن مكنوناته، وتطوير معارفه ، ومهاراته، وقيمه. • معلم التربية الفنية في البحث: هو الثخص المؤهل المعين من قبل وزارة التربية في الكويت للقيام بتدريس منهج التربية الفنية في المرحلة الابتدائية. 8 ـ الدراسات السابقة: 1 1. دراسة (الرزين، 2005)، السعودية: بعنوان (برنامج علاجي مقترح في التربية الفنية لذوي صعوبات تعلم الرياضيات في الصف الثاني الابتدائي). هدفت الدراسة إلى تعرف فاعلية برنامج علاجي في التربية الفنية لذوي صعوبات تعلم الرياضيات في الصف الثاني الابتدائي، وذلك من خلال تنمية القدرات الإدراكية، والمساعدة في حل المشكلات الرياضية، واستخدم المنهج شبه التجريبي على حالة واحدة، وتوصلت الدراسة إلى وجود فاعلية للبرنامج المستخدم، ودور التربية الفنية في معالجة صعوبات التعلم النمائية والأكاديمية من خلال تتمية التمييز البصري، وتتمية الذاكرة البصرية، وتتمية التركيز ومحاولة

خفض تثتيت الانتباه. 2. دراسة (الزهراني، 2005)، السعودية: بعنوان: دور المعارض المدرسية في إنماء التذوق الفني لدى التلاميذ في مرحلة التعليم العام (المرحلة المتوسطة). هدفت الدراسة إلى التأكيد على إنماء التذوق الفني كهدف من أهداف مادة التربية الفنية، وما تساهم به المعارض المدرسية الحالية من دور لتحقيق ذلك الهدف، واستخدم المنهج الوصفي، واستخدم استبانة لتعرف دور المعارض المدرسية في إنماء التذوق الفني لاى التلاميذ في مرحلة التعليم العام(المرحلة المتوسطة، وشملت عينة الدراسة على(100) دعلى معلماً ومشرفاً لمادة التربية الفنية، وكان أبرز نتائج الدراسة: إن أداء المعارض المدرسية الحالية في المجال التربوي يحتاج إلى تركيز أكثر لتفعيل دورها التربوي بشكل صحيح، والمعارض المدرسية كونها تقوم بعرض الأعمال الفنية فهي نافذة جيدة لإنماء التذوق الفني، وهذا لتها الجانب حالياً لا يتم تفعيله بالقدر المطلوب، وينت الدراسة عدم اهتمام المعلم باستغلال المعرض المدرسي في إنماء التذوق بمان 
الفني من خلال جدولة مهام المعرض، وتفعيل دوره الفني في هذا الجانب، وكانت أبرز المعوقات التي تواجه معلم التربية الفنية تتمثل في: كثرة عدد التلاميذ، الخبرات السلبية التي تكونت لاى التلميذ عن التربية الفنية، توفر الإمكانيات. 3. دراسة (عبد النبي، 2008)، مصر : بعنوان (فاعلية استخدام العلاج بالفن (الرسم) في التخفيف من الوحدة النفسية لاي عينة من طلاب الجامعة / دراسة (كلينيكية).

هدفت الدراسة إلى التعرف على فاعلية استخدام العلاج بالفن(الرسم) في التخفيف من الثعور بالوحدة النفسية لاي عينة من

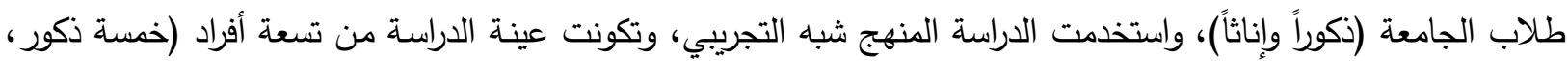

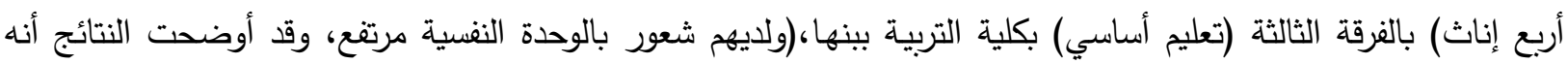
توجد فروق ذات دلالة إحصائية بين رتب درجات أفراد عينة الدراسة (الذكور والإناث) على مقياس "الثعور بالوحدة النفسية " قبل استخدم العلاج بالفن(الرسم)، وبين رتب درجاتهم بعد تطبيق العلاج بالفن(الرسم) عند مستوي، وذلك لصالح الطلاب والطالبات في القياس البعدي، وعن وجود فروق ذات دلالة إحصائية بين رتب درجات أفراد عينـة الدراسة (الذكور والإناث)

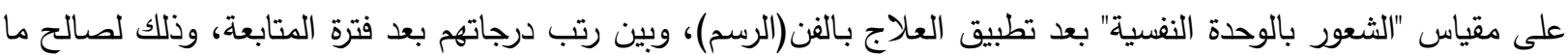

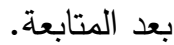

4. دراسة (الزهراني، 2010)، السعودية: بعنوان: (دور الدورات التدرببية في تطوير المهارات التدريسية لمعلمي التربية

\section{(الفنية من وجهة نظرهم).}

هدفت الدراسة إلى معرفة أهمية الدورات التدريبية لمعلمي التربية الفنية من وجهة نظرهم. وتحديد مدى استفادة معلمي التربية

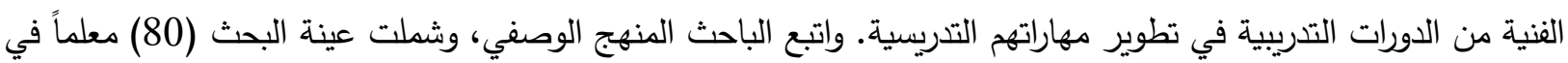
التربية الفنية، وقام الباحث ببناء استبانة مكونة من ثلاثة محاور، ومن أبرز نتائج الدراسة: أشارت النتائج إلى أهمية الدورات التدريبية لمعلمي التربية الفنية بدرجة كبيرة، ووجود فروق ذات دلالة إحصائية في المؤهل العلمي لصالح البكالوريوس، وعدم التهاء

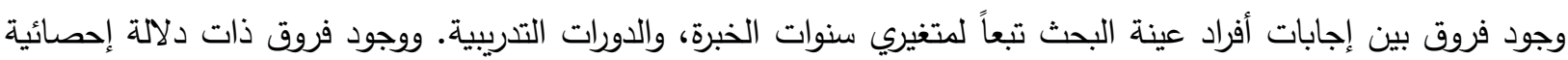
في المرحلة التعليمية لصالح المرحلة الابتدائية. 5. دراسة (جرادات وقبالي، 2013)، السعودية: بعنوان (اتجاهات المعلمين نحو مشكلة صعوبات التعلم في المدارس الأساسية في الأردن).

هدفت الدراسة إلى التعرف على اتجاهات المعلمين نحو مشكلة صعوبات التعلم، والتركيز على الجوانب الإيجابية منها، ومعالجة الجوانب السلبية، ومواطن الضعف، واعتمدت الدراسة على المنهج الوصفي التحليلي ، وتم تصميم استبانة، وبلغ عدد ولديل

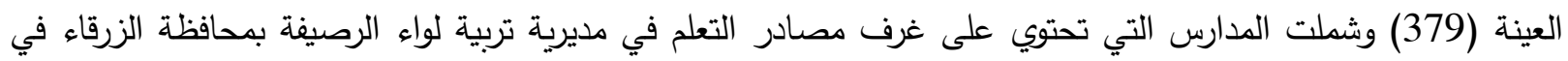

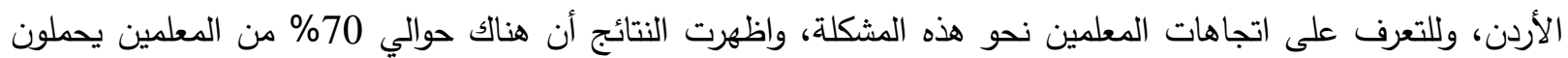
اتجاهاً ايجابياً نحو هذه المشكلة، وأن 30\% منهم يحملون اتجاها سلبيا نحو هذه المشكلة، وأن هنالك فروقًا ذات دلالة هندات إحصائية، تبعًا للمتغيرات الثثلاثة الجنس، وسنوات الخبرة، والمستوى التعليمي. وان. 6. دراسة (شبيطة وبصلات، 2015)، فلسطين: بعنوان (دور برنامج التأهيل المجتمعي (CBR) في دمج الأطفال ذوي صعوبات التعلم في المدارس).

هدفت الدراسة إلى تعرف دور برنامج التأهيل المجتمعي (CBR) في دمج الأطفال ذوي صعوبات التعلم في المدارس من

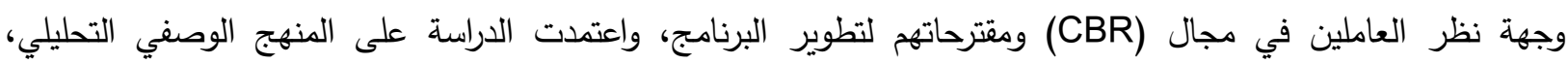
وتكونت عينة الدراسة من (52) موظفاً وموظفة يعملون في برنامج (CBR) في المحافظات الثمالية في فلسطين، وبينت

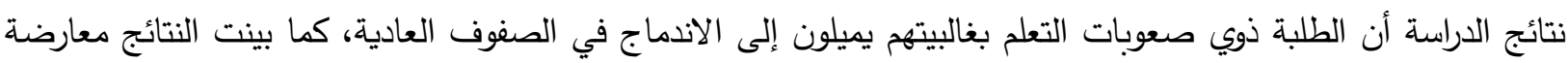

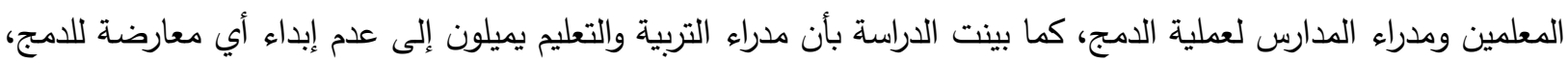


وأوضحت الدراسة التوجهات السلبية التي يحملها الكادر التعليمي العامل في العملية التعليمية اتجاه الطلبة ذوي صعوبات

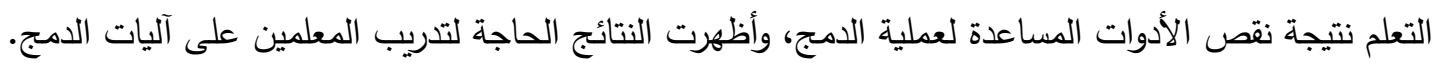
7. دراسة (بريطل، 2017)، الجزائر: بعنوان (فاعلية برنامج تدريبي قائم على الفن التشكيلي لتأهيل أطفال التوحد).

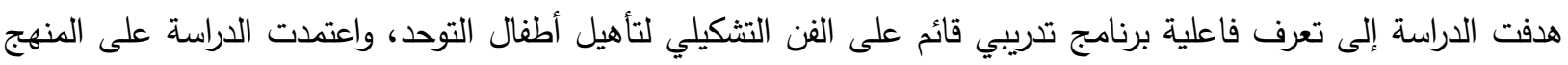
شبه التجريبي، وتكونت عينة الدراسة من (3) حالات لأطفال شُخصوا على أنهح يعانون من مستوى بسيط لسلوك يتعلق

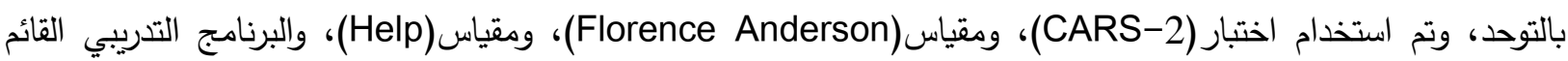
على الفن التثكيلي، لتأهيل أطفال التوحد، للباحث عوض بن مبت مبارك اليامي(2006)، وقد توصلت الدراسة الحالية إلى وجود فروق بين القياس القبلي والقياس البعدي، في اكتساب المهارات اللغوية، والإدراكية والانفعالية، والاجتماعية والبدنية، لدى

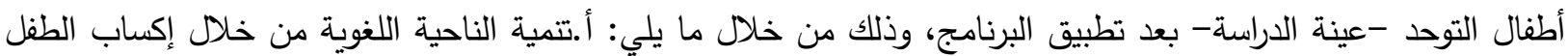
بعض المفردات اللغوية. ب. تتمية الناحية الإدراكية من خلال التعرف على الأشكال والألوان، وتسميتها واستعمالاتها. ج. تتمية بعض القدرات العضلية لاى الطفل، من خلال ممارسة النشاطات الفنية. د. تتمية الناحية الانفعالية من خلال الأنثطة الصغيرة الناجحة. هـ. تتمية التواصل الاجتماعي من خلال ممارسة الأنشطة الفنية. وتم إكساب الأطفال المفردات اللغوية المستهدفة في البرنامج التدرببي لتأهيل الأطفال.

10/2 - الدراسات الأجنبية:

1. دراسة كنيث وتومي (Keneth \& Tommy, 1996)، الولايات المتحدة الأمريكية: بعنوان: A survey of art Teachers Needs

(الاحتياجات التدريبية لمعلمي التربية الفنية). هدفت الدراسة إلى تحديد الاحتياجات التدريبية لمعلمي التربية الفنية في المرحلة الثانوية بولاية جورجيا الأمريكية، وكذلك التعرف على الفروق بين متوسطات درجات الاحتياجات التدريبية لمعلمي التربية الفنية وفقاً لمتغير الخبرة، وتمَّ إعداد استبانة

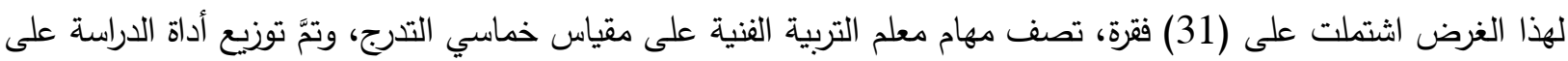
أفراد العينة البالغ (922) معلماً ومعلمة، ومن أهم نتائج الدراسة: أجاب معلمو التربية الفنية على أهم الاحتياجات التدريبية

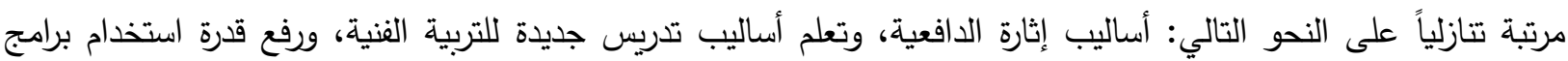
الحاسوب المتعلقة بالرسم، وتدريس الطلبة ذوي التحصيل المرتفع، ومعرفة الحركات الفنية المعاصرة. كما توجد فروق ذات دلالة إحصائية بين متوسطات درجات أفراد عينة البحث على الاحتياجات التدريبية لمعلمي التربية الفنية تعزى إلى متغير الخبرة لصالح المعلمين حديثي التعيين. 2. دراسة أهن (Ahn, 2003)، الولايات المتحدة الأمريكية: بعنوان: Instructional Use of the Internet by high school art teachers in Missouri.

(الاستخدامات التربوية للإنترنت في مجال التربية الفنية في المدارس الثانوية في مدارس ولاية ميزوري الأمريكية). هدفت الدراسة إلى استجلاء مدركات عينة الدراسة حول تطبيقات الإنترنت وفوائدها في تحسين تدريس التربية الفنية والفن التثكيلي مع التركيز على نموذج التربية الفنية القائم على التتظيم المعرفي. ولتحقيق هدف الدراسة صممت الباحثة استبانة وقامت بإرسالها لعينة الدراسة والتي بلغ إجمالي عددهم (349) معلماً للتربية الفنية. وقد أسفرت الدراسة عن النتائج التالية :

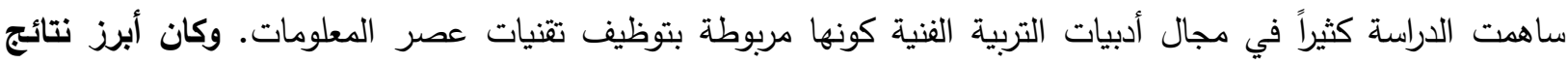
الدراسة أن معلمي التربية الفنية كانوا إلى حد ما أقدر على تتفيذ مناهج التربية الفنية القائمة على التتظيم المعرفي في إطار الاستفادة من تطبيقات الإنترنت مع تتمية وتحسين قدراتهم في تدريس الثقافة البصرية وذلك بتفحص الاستخدامات التعليمية 
3. دراسة بيفالو (Pifalo, 2006)، الولايات المتحدة الأمريكية: بعنوان:

Art Therapy with Sexually Abused Children and Adolescents.

(العلاج بالفن مع الأطفال والمراهقين الذين تعرضوا لسوء المعاملة والايذاء الجنسي). وكانت دراسة بفالو (2006 Pifalo) لمعرفة أثر العلاج الجماعي بالفن " الرسم "والعلاج المعرفي السلوكي على الأطفال، ومراهقات ضحايا الإيذاء الجنسي، تراوحت أعمارهن بين (8 - 17)عاماً، وكان العلاج لمدة (8) أسابيع، في كل أسبوع

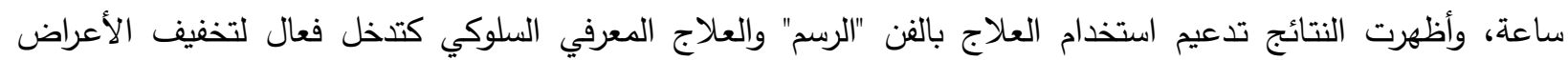
المرتبطة بالإيذاء الجنسي في الطفولة، ويذكر الباحث أن خبرة الإيذاء الجنسي في الطفولة، خبرة مؤلمة غير لفظية، والعلاج

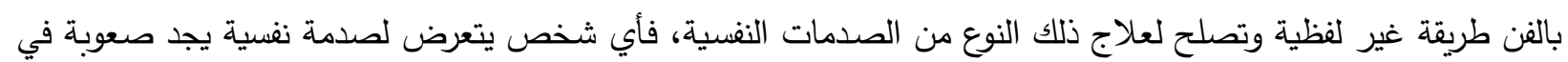
التعبير عن تجربته بشكل مباشر ولفظي، والعلاج بالفن "الرسم" يعتبر نوعاً من العلاج يتيح الفرصة للتعبير غير اللفظي. 4. دراسة غوغنهايم (Guggenheim, 2006)، الولايات المتحدة الأمريكية: بعنوان: Evaluating Impact of Arts Education on Literacy.

(تقييم أثر تعليم الفنون على محو الأمية). هدف الدراسة إلى معرفة أثر تعليم الفنون على محو الأمية وتألفت عينة الدراسة من الطئ). الثالث في مدينة نيويورك في أربع مدارس اختيرت وفقاً لمعايير ديموغرافية واجتماعية واقتصادية واعتمدت الدراسة على الدى إجراء

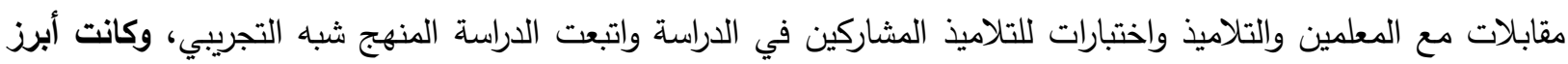
نتائج الاراسة: توصلت إلى أن تعليم الفنون يزيد من مهارات القراءة والكتابة ومهارات التفكير الناقد، كما وجدت والتيل الدراسة أن الطلاب الذين شاركوا في برنامج غوغنهايم يستخدمون المزيد من الكلمات للتعبير عن أنفسهم وإثباتها، وارتفاع مهارات القراءة

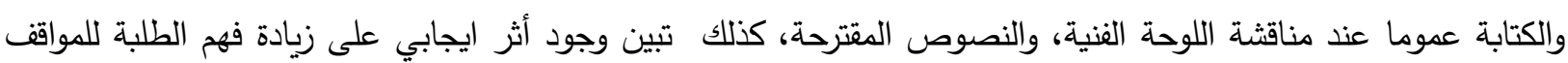

5. دراسة ستيلزر وآخرون(Stelzer et al, 2007)، الولايات المتحدة الأمريكية: بعنوان: Art Therapy for Adolescents with Posttraumatic Stress Disorder Symptoms.

(العلاج بالفن للمراهقين الذين يعانون من أعراض اضظراب ما بعد الصدمة). وكانت دراسة ستيلزر وآخرين لمعرفة فاعلية التدخل العلاجي المساعد بواسطة الفن في الحد من اضطراب ما بعد الصدمة

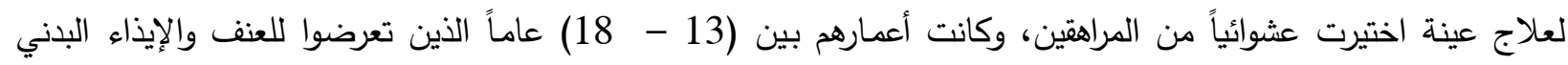
والجنسي في الطفولة، وكانت المقارنة بين طريقتين كل منهما عبارة عن جلسة جماعية لمدة ساعة واحدة على مدى 16 أسبوعا: (أ) بروتوكول علاج بالفن معبرة مع التركيز على الصدمات و (ب) حالة العلاج بدون استخدام الفن، ، وتم تقييمهح

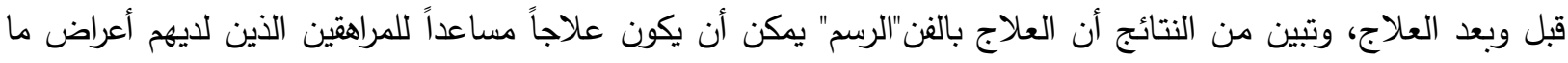

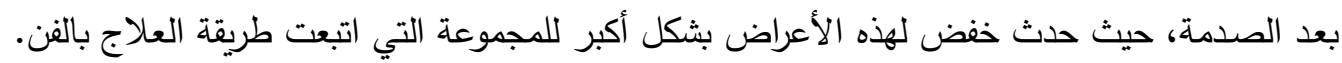
6. دراسة سكروجز وبريغهام وماستروبيري (Scruggs, Brigham, Mastropieri,2013)، الولايات المتحدة الأمريكية: بعنوان:

Common Core Science Standards: Implications for Students with Learning Disabilities

(معايير العلوم الأساسية المشتركة: الآثار المترتبة على الطلاب ذوي صعوبات التعلم)

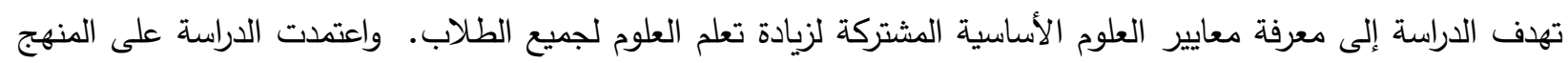
الوصفي التحليلي، وبينت الدراسة النتائج الآتية: تثمل المعايير التركيز على جوانب اللغة الإنجليزية والفنون اللغوية في تعلم العلوم، وثلاثة أبعاد للمعايير العلمية، بما في ذلك ممارسات العلم، ومفاهيم العلوم الثاملة، والأفكار الأساسية في مختلف الإنف 
المجالات. والعديد من هذه القضايا تجلب آثاراً هامة على الطلاب ذوي صعوبات التعلم، وبينت الدراسة الدعم المناسب والتطبيقات التي من المكن للطلاب ذوي صعوبات التعلم الاستفادة بشكل كبير من هذه المعايير الجديدة . ومع ذلك قده دلد تتطلب متطلبات هذه المعايير مستوى أعلى من الدعم من تلك المتاحة عادة لكثير من الطلاب ذوي صعوبات التعلم. 7. دراسة سالدانا (Saldana, 2016) الولايات المتحدة الأمريكية: بعنوان:

Children with Disabilities: Constructing Metaphors and Meanings through Art

(الأطفال ذوي الإعاقة: بناء التعابير والمعاني من خلال الفن) تهدف من هذه الدراسة النوعية هو استكثاف كيف أن الفن، كأداة شبه سيميائية، يحول الأطفال ذوي الإعاقة ويبني التعابير والدعاني. ولإنجاز هذا الهدف يجب علينا الإصغاء إلى المعلمين والقائمين على رعاية الأطفال العاملين في ميدان التربية الخاصة. واعتمدت الدراسة المنهج الوصفي التحليلي، واستخدمت استبانة موجهة للعاملين في مركز رعاية الأطفال في الولايات المتحدة الأمريكية، وخلصت الدراسة إلى أن هناك ثلاث فئات رئيسية من خلال تحليل البيانات: 1) منظور المعلمين للفن؛ 2. 2)

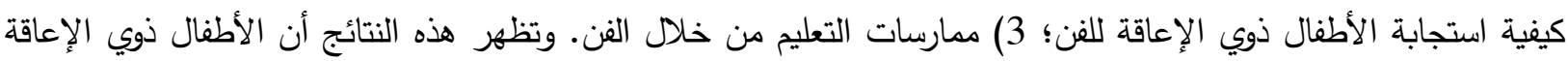
يمكن أن يقيموا رابط مع المعلين من خلال الموسيقى. ومن خلال الموسيقى يمكن للمعلمين معرفة ماذا يريد الطفل، وماذا

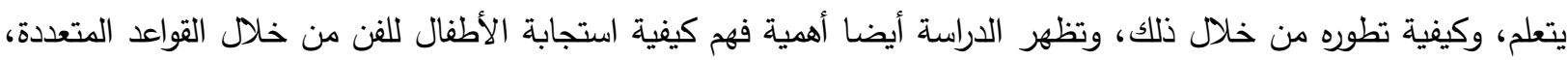
وتطوير الممارسات الروتينية. وبالإضافة إلى ذلك تؤكد الدراسة ضرورة مواصلية واصلة البحث في مجال الفن، والسيميائية، والأطفال ذوي الإعاقة.

\section{0/3 ـ التعليق على الاراسات السابقة :}

تتاولت الدراسات السابقة دور برنامج التأهيل التأهيل المجتمعي (CBR) في دمج الأطفال ذوي صعوبات التعلم في المدارس،

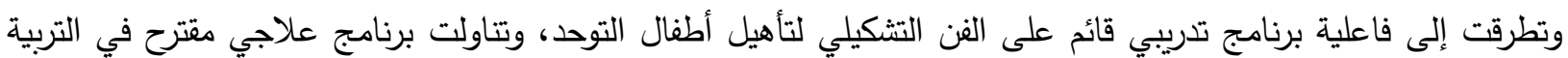

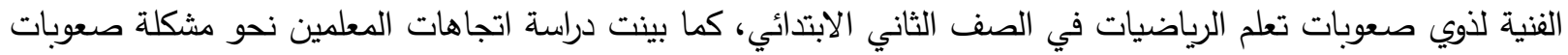
التعلم في المدارس الأساسية في الأردن، كما تتاولت دور المعارض الددرسية في إنماء التذوق الفني لدى التلاميذ في مرحلة التعليم العام (المرحلة المتوسطة)، كما تطرقت الدراسات السابقة إلى دور الدورات التدريبية في تطوير المهارات التدريسية

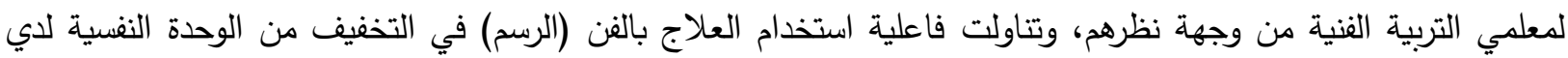
عينة من طلاب الجامعة / دراسة اكلينيكية، وكذلك الاحتياجات التدربيية لمعلمي التربية الفنية، والاستخدامات التربوية للإنترنت في مجال التربية الفنية في المدارس الثانوية في مدارس ولاية ميزوري الأمريكية، كما تم تتاول دراسة العلاج بالفن مع الأطفال والمراهقين الذين تعرضوا لسوء المعاملة والايذاء الجنسي، وكذلك دراسة معرفة أثر تعليم الفنون على محو الأمية، ودراسة العلاج بالفن للمراهقين الذين يعانون من اضطراب ما بعد الصدمة، ودراسة الأطفال ذوي الإعاقة: بناء التعابير والمعاني من خلال الفن، وتتاولت دراسة معايير العلوم الأساسية المشتركة: الآثار المترتبة على الطلاب ذوي صعوبه دمبات التعلم. ما يميز البحث الحالي إنه يسعى إلى تعرف متطلبات التربية الفنية لدعم ذوي صعوبات التعلم في المدارس (المرحلة الابتدائية) بمحافظة الجهراء من وجهة نظر معلمي التربية الفنية إذ يتفق مع الدراسات السابقة من حيث تتاولها لصعوبات التعلم، ودور الفن في دعم فئة ذوي صعوبات التعلم، وكذلك يتقق من حيث تتاولها بعض الدراسات لمسألة معرفة دور التربية

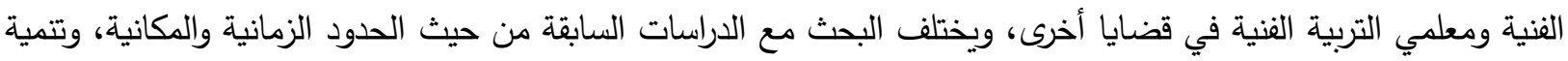

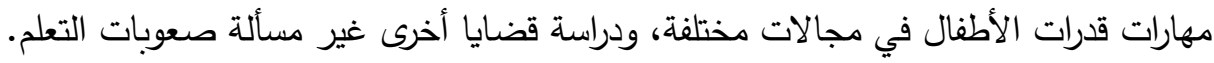
11 ـ إجراءات الدراسة الميدانية: 
يعتمد البحث على المنهج الوصفي التحليلي الذي يحاول "وصف طبيعة الظـاهرة موضـع البحث، فالمنهج الوصفي

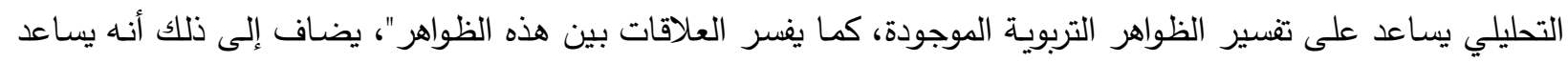

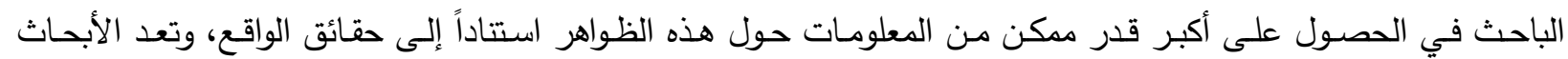

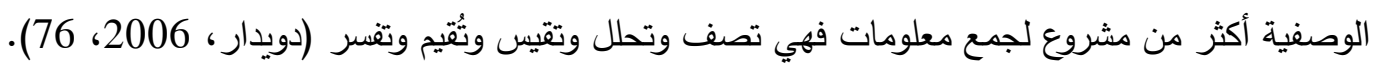

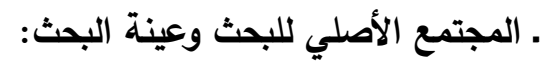
1. المجتمع الأصلي البحث: يتكون المجتمع الأصلي من جميع المعلمين والمعلمات العاملين في تدريس مقرر التربية الفنية في مدارس المرحلة الابتدائية الحكومية في مدينة الجهراء بالكويت، حيث يبلغ عددهم بحسب إحصائيات وزارة التربية في لئي الكويت للعام الدراسي /2017 - 2018/ (160) معلماً ومعلمة تربية فنية.

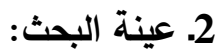

لقد تم تطبيق أداة البحث على عينة عشوائية بلغت (80) معلماً ومعلمة تربية فنية في مدينة الجهراء بنسبة 50\%.

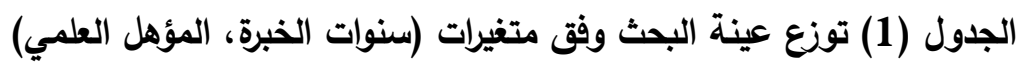

\begin{tabular}{|c|c|c|c|}
\hline النسبة & العدد & الفئة & المتغير \\
\hline$\% 42.50$ & 34 & أقل من 5 سنوات & \multirow{5}{*}{ سنوات الخبرة } \\
\hline$\% 20$ & 16 & من 5- وأقل من 10 سنوات & \\
\hline$\% 22.50$ & 18 & من 10- وأقل من 15 سنة & \\
\hline$\% 15$ & 12 & 15 سنة فأكثر & \\
\hline$\% 100$ & 80 & المجموع الكلي & \\
\hline$\% 22.50$ & 18 & معهد دبلوم أو مايعادله & \multirow{4}{*}{ العلمي } \\
\hline$\% 62.50$ & 50 & بكالوريوس (جامعي) & \\
\hline$\% 15$ & 12 & دراسات عليا & \\
\hline$\% 100$ & 80 & المجموع الكلي & \\
\hline
\end{tabular}

3. - 3 - أداة البحث:

1- استبانة متطلبات التربية الفنية لدعم ذوي صعوبات التعلم في المدارس (المرحلة الابتدائية) بمحافظة الجهراء من وجهة

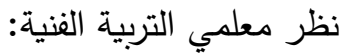
- مرحلـة الاطـلاع واختيـار بنـود الاستبانة: تم فيها الاطـلاع على بعض الدراسـات التي تتاولت موضـوع التربية الفنيةـ، وصعوبات التعلم، وقد اختار الباحث الدراسات العربية الحديثة في هذا المجال، ثم حدد الباحث في ضوء الدراسات السابقة،

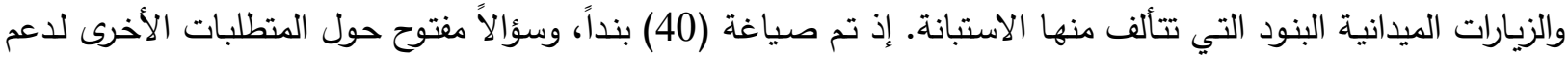
ذوي صعوبات التعلم. 2- الاراسة الاستطلاعية لاستبانة البحث: بهدف التحقق من وضوح بنود الاستبانة وتعليماته، قام الباحث بدراسة استطلاعية، إذ طبق الاستبانة على عينة صغيرة بلغت (35) معلماً ومعلمةً، ونتيجة للدراسة الاستطلاعية، بقيت بنود الاستبانة كما هي؛ وكذلك التعليمات المتعلقة بها، حيث تبين أنها واضحة تماماً ومفهومة. 3-3 طريقة تصحيح استبانة البحث: تتم الإجابة على بنود الاستبانة بواحدة من الإجابات التالية: (موافق، إلى حد ما، غير موافق). فالعبارات تُعطى درجاتها

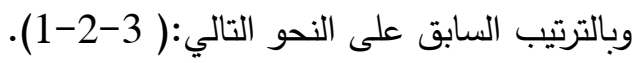


4 - صدق استبانة البحث:

. صدق المحكمين (الصدق الظاهري):

استخدم الباحث طريقة الصدق الظاهري بهدف التحقق من صلاحية بنود استبانة البحث، تمَّ عرض الاستبانة على عدد من

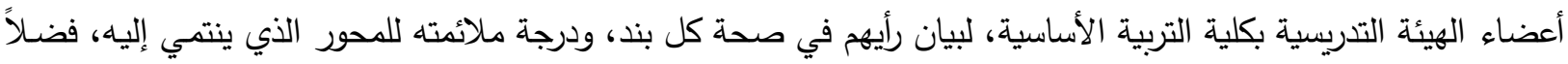

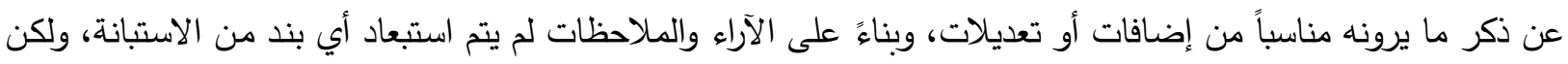
تم تعديل بعضها من حيث الأسلوب والصياغة؛ ونذكر على سبيل المثال:

\begin{tabular}{|c|c|}
\hline البنود بعد التعديل & البنود قبل التعديل \\
\hline يستخدم معلم التربية الفنية استراتيجيات تعليمية تراعي الفروق & يستخدم المعلم استراتيجيات تعليمية مختلفة. \\
\hline 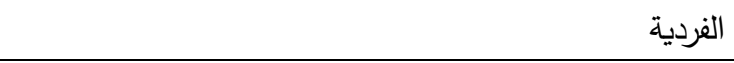 & \\
\hline يصنف التلاميذ الأشكال المختلفة من خلال الأنشطة الفنية. & يقوم التلاميذ بتصنيف الأشكال المختلفة ضمن الأنثطة الفنية. \\
\hline
\end{tabular}

وبلغ المجموع النهائي لبنود هذه الاستبانة بصورته النهائية (40) بنداً تم توزيعها بصورة منتظمة في الاستبانة.

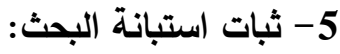

اعتمد الباحث في حساب ثبات الاستبانة على الطريقتين التاليتين: • إعادة التطبيق: تم حساب معامل الثبات عن طريق تطبيق الاستبانة وإعادة تطبيقه على نفس العينة بعد أسبوعين،وجاءت النتائج كالآتي:

الجدول (2) معامل الترابط (بيرسون) في التطبيقين الأول والثاني لاستبانة البحث

\begin{tabular}{|c|c|c|}
\hline القرار & معامل الترابط (بيرسون) & أبعاد استبانة البحث \\
\hline دالة عند (0.01) & 0.796 & الارجة الكلية \\
\hline
\end{tabular}

أظهرت النتائج في الجدول السابق تمتع الاستبانة بدرجة عالية من الثبات بلغت (0.796).

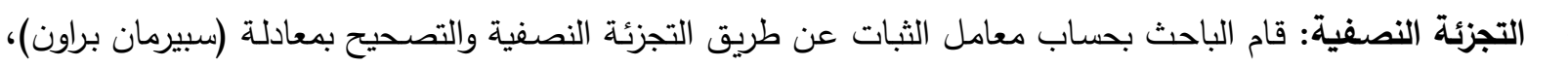
وكانت النتائج كما يشير إليها الجدول الآتي:

الجدول (3) قيمة معادلة (سبيرمان براون) لاستبانة دور الدورات التدريبية

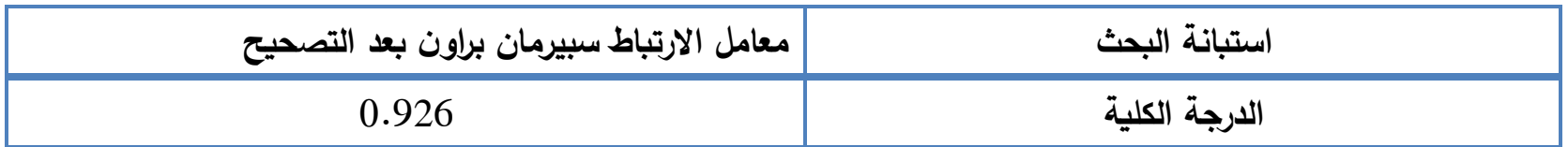

يتضح من الجدول السابق أن قيمة (سبيرمان براون) مرتفعة، وتدل على درجة عالية من الثبات. 12 ـ مناقشة نتائج أسئلة البحث وفرضئ لجنياته:

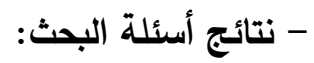

للإجابة عن أسئلة البحث تم اعتماد المعيار التالي: إذ جرى حساب الدرجة المعيارية بناء على المعادلة: القيمة العليا للبديل القيمة الدنيا للبديل : عدد المستويات، وتم تقسيم الدرجات إلى ثلاثة مستويات كما يبينه الجدول رقم (4): الجدول رقم (4) يبين الارجة المعيارية للحكم على استبانة البحث

\begin{tabular}{|c|c|c|}
\hline التقدير & الارجة & المستويات \\
\hline منخفض & $1-1.66$ & المستوى الأول \\
\hline متوسط & $1.67-2.32$ & المستوى الثاني \\
\hline
\end{tabular}


1. ما واقع التربية الفنية في دعم ذوي صعوبات التعلم في المدارس الابتدائية في الجهاء ومتطلباتها من وجهة نظر معلمي التربية الفنية؟. للإجابة عن هذا السؤال تم حساب المتوسط الحسابي والانحراف المعياري لدرجات المعلمين في استبانة البحث (البعد الأول)، كما يبينه الجدول رقم (5):

الجدول (5) المتوسط الحسابي والانحراف المعياري لاستجابة عينة البحث على استبانة البحث (البعد الأول)

\begin{tabular}{|c|c|c|c|c|}
\hline \multicolumn{5}{|c|}{ البعد الأول: واقع التربية الفنية في دعم الأطفال ذوي صعوبات التعلم } \\
\hline ترتيب & الانحراف & المتوسط & 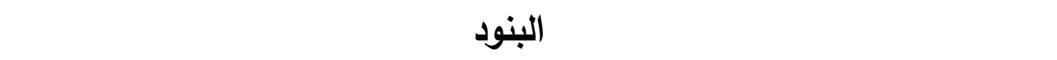 & b \\
\hline 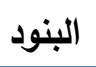 & المعياري & الحسابي & & \\
\hline 11 & 0.526 & 1.54 & تتضمن أهداف التربية الفنية أهدافاً تراعي الأطفال ذوي صعوبات التعلم. & 1 \\
\hline 14 & 0.499 & 1.44 & يتضمن منهج التربية الفنية دروساً تتمي قدرات الأطفال ذوي صعوبات التعلم. & 2 \\
\hline 11 & 0.502 & 1.54 & يتضمن منهج التربية الفنية أنشطة صفية تتمي قدرات الأطفال ذوي صعوبات التعلم. & 3 \\
\hline 15 & 0.476 & 1.34 & يتضمن منهج التربية الفنية أنشطة لا صفية تتمي قدرات الأطفال ذوي صعوبات التعلم. & 4 \\
\hline 7 & 0.393 & 1.81 & تعتدد أنشطة التعلم على استخدام حواس متعددة (بصر - لمس - سمع - حس حركي) & 5 \\
\hline 4 & 0.557 & 2.24 & يصنف التلاميذ الأشكال المختلفة من خلال الأنثطة الفنية. & 6 \\
\hline 2 & 0.506 & 2.35 & يميز التلاميذ بين الأشكال المختلفة من خلال فن تشكيل المعجون. & 7 \\
\hline 1 & 0.490 & 2.61 & يقوم التلاميذ بأنشطة لتتمية قدراتهم العضلية مثل تثكيل الطين أو الورق. & 8 \\
\hline 5 & 0.449 & 2.23 & ينظم المعلم أنشطة فنية لتتمية مهارة التمييز البصري لدى التلاميذ. & 9 \\
\hline 6 & 0.295 & 1.96 & ينمي المعلم مهارات التلاميذ اللغوية من خلال الأنشطة الفنية. & 10 \\
\hline 3 & 0.497 & 2.26 & يقوم التلاميذ بأنشطة فنية تهدف إلى إدراك المسافة والحجم والبعد للأشياء. & 11 \\
\hline 13 & 0.503 & 1.50 & يستخدم المعلم استراتيجيات تعليمية تراعي الفروق الفردية. & 12 \\
\hline 9 & 0.436 & 1.75 & يوفر المعلم جو تعلم مناسب لجميع التلاميذ. & 13 \\
\hline 12 & 0.503 & 1.51 & يستخدم المعلم أساليب التعلم بالملاحظة. & 14 \\
\hline 8 & 0.680 & 1.76 & يشجع المعلم التواصل بين التلاميذ. & 15 \\
\hline 4 & 0.750 & 2.24 & يوجد في المدرسة تقنيات تعليمية متتوعة. & 16 \\
\hline 16 & 0.436 & 1.25 & يتعاون المعلم مع المرشد أو الاختصاصي التربوي لدعم التلاميذ وتتمية قدراتهم. & 17 \\
\hline 16 & 0.436 & 1.25 & تتعاون المدرسة مع الأهل لدعم التلاميذ وتتمية قدراتهم. & 18 \\
\hline 10 & 0.480 & 1.65 & تتعاون الإدارة مع المعلم لتأمين كل السبل لدعم التلاميذ وتتمية قدراتهم. & 19 \\
\hline \multirow[t]{2}{*}{17} & 0.371 & 1.16 & توضع خطط فردية لمساعدة الأطفال ذوي صعوبات التعلم. & 20 \\
\hline & 0.489 & 1.76 & الارجة الكلية & \\
\hline
\end{tabular}


يلاحظ من الجدول رقم (5) أنَّ البنود المتعلقة بالبعد الأول، تراوحت متوسطاتها بين (1.23 و 2.61). بينت النتائج أن قيمة المتوسط الكلي (1.76) وهي تقع ضمن التقدير المتوسط مما يدل على وجود حاجة ومتطلبات لتطوير واقع التربية الفنية في مجال دعم الأطفال ذوي صعوبات التعلم، وخصوصاً في البنود التي تتاولت مسألة الخطط الفردية لمساعدة الأطفال ذوي صعوبات التعلم، والتعاون بين المدرسة والأهل، والتعاون بين المعلم والمرشد، ومسألة تضمين المنهج بأهداف، ودروس، وأنشطة صفية ولا صفية لدعم الأطفال ذوي صعوبات التعلم ، وهذا ما أكدت عليه دراسة(الرزين، 2005)، ودراسة (بريطل، 2017)، ودراسة (ستيلزر وآخرون،2007)، ودراسة (بيفالو، 2006)، إذ بينت بعض هذه الدراسات فاعلية دور الفن في مساعدة ودعم الأطفال ذوي صعوبات التعلم، والدراسات الأخرى بينت فاعلية الفن في دعم الأطفال ذوي الحتياجات الخاصة، والأشخاص الذين يعانون من بعض الاضطرابات النفسية.

2. ما متطلبات التربية الفنية لاعم الأطفال ذوي صعوبات التعلم في المدارس في المدارس الابتدائية في محافظة الجهاء من وجهة نظر معلمي التربية الفنية؟. الجدول (6) المتوسط الحسابي والانحراف المعياري لاستجابة عينة البحث على استبانة البحث (البعد الثاني)

\begin{tabular}{|c|c|c|c|c|}
\hline \multicolumn{5}{|c|}{ البعد الثاني: متطلبات التربية الفنية لاعم الأطفال ذوي صعوبات التعلم } \\
\hline ترتيب & 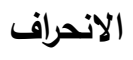 & 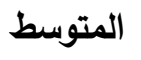 & 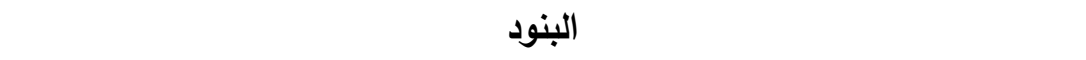 & م \\
\hline 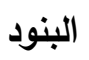 & المعياري & الحسابي & & \\
\hline 16 & 0.499 & 2.56 & وضع أهداف لمادة التربية الفنية تراعي الأطفال ذوي صعوبات التعلم. & 21 \\
\hline 10 & 0.436 & 2.75 & تأليف دروساً لمادة التربية الفنية تتمي قدرات الأطفال ذوي صعوبات التعلم. & 22 \\
\hline 8 & 0.403 & 2.80 & تتظيم أنشطة صفية تتمي قدرات الأطفال ذوي صعوبات التعلم. & 23 \\
\hline 9 & 0.420 & 2.78 & تتظيم أنشطة لا صفية تتمي قدرات الأطفال ذوي صعوبات التعلم. & 24 \\
\hline 11 & 0.443 & 2.74 & تنظيم أنشطة تعلم تستخدم فيها الحواس المتعددة (بصر - لمس - سمع - حس & 25 \\
\hline 13 & 0.455 & 2.71 & وضع أنشطة فنية بهاف تتمية مهارة تصنيف الأشكال المختلفة. & 26 \\
\hline 14 & 0.461 & 2.70 & وضع أنثطة فنية بهدف تتمية مهارة تمييز الأثكال المختلفة. & 27 \\
\hline 1 & 0.157 & 2.98 & تتظيم أنثطة فنية لتتمية قدرات التلاميذ العضلية مثل تثكيل الطين أو الورق. & 28 \\
\hline 3 & 0.244 & 2.94 & وضع أنشطة فنية لتتمية مهارة التمييز البصري لدى التلاميذ. & 29 \\
\hline 13 & 0.455 & 2.71 & تتظيم أنشطة لتتمية مهارات التلاميذ اللغوية. & 30 \\
\hline 15 & 0.466 & 2.69 & تتظيم أنثطة فنية تهدف إلى إدراك المسافة والحجم والبعد للأشياء. & 31 \\
\hline 3 & 0.244 & 2.94 & تدريب المعلم على استخدام استراتيجيات تعليمية تراعي الفروق الفردية. & 32 \\
\hline 3 & 0.244 & 2.94 & تدريب المعلم على أساليب تهيئة جو تعلم مناسب لجميع التلاميذ. & 33 \\
\hline 4 & 0.302 & 2.90 & تدريب المعلم على التعامل مع الأطفال ذوي صعوبات التعلم. & 34 \\
\hline 7 & 0.382 & 2.83 & تدريب المعلم على مهارات التواصل. & 35 \\
\hline
\end{tabular}




\begin{tabular}{|c|c|c|c|c|}
\hline 12 & 0.449 & 2.73 & تأمين تقنيات تعليمية متتوعة. & 36 \\
\hline 6 & 0.371 & 2.84 & التعاون بين المعلم والمرشد أو الاختصاصي التربوي لدعم التلاميذ وتتمية قدراتهم. & 37 \\
\hline 5 & 0.333 & 2.88 & التعاون بين المدرسة والأهل لدعم التلاميذ وتتمية قدراتهم. & 38 \\
\hline 5 & 0.333 & 2.88 & التعاون بين الإدارة والمعلم لتأمين كل السبل لدعم التلاميذ وتتمية قدراتهم. & 39 \\
\hline \multirow[t]{2}{*}{2} & 0.219 & 2.95 & وضع خطط فردية لمساعدة الأطفال ذوي صعوبات التعلم. & 40 \\
\hline & 0.365 & 2.81 & الارجة الكلية & \\
\hline
\end{tabular}

يلاحظ من الجدول رقم (6) أنَّ البنود المتعلقة بالبعد الثاني ، تراوحت متوسطاتها بين (2.56 و 2.98). بينت النتائج أن قيمة المتوسط الكلي (2.81) وهي تقع ضمن التقدير المرتفع مما يدل على وجود حاجة كبيرة إلى متطلبات تطوير واقع التربية الفنية لاعم الأطفال ذوي صعوبات التعلم، وخصوصاً في البنود التي تتاولت الآتي: تنظيم أنشطة فنية لتتمية قدرات التلاميذ العضلية مثل تثكيل الطين أو الورق، إذ بلغ المتوسط الحسابي لها (2.98)، ووضع خطط فردية لمساعدة الأطفال ذوي صعوبات التعلم إذ بلغ المتوسط الحسابي لها (2.95). و وضع أنشطة فنية لتتمية مهارة التمييز البصري لدى التلاميذ، وتدريب المعلم على استخدام استراتيجيات تعليمية تراعي الفروق الفردية، وتدريب المعلم على أساليب تهيئة جو تعلم مناسب لجميع التلاميذ إذ بلغ المتوسط الحسابي لكل منهما (2.94)، وهذا ما أكدت عليه دراسة (شبيطة وبصلات، 2015) إذ خلصت إلى ضرورة تدريب المعلمين على التعامل مع الأطفال ذوي صعوبات التعلم، وآلية دمجهم في المدارس، وتوفير المستلزمات المناسبة لذلك، وكذلك خلصت دراسة(سكروجز وبريغهام وماستروبيري، 2013) إلى ضرورة وضع المعايير للتعلم لما له من آثار ايجابية لدعم ذوي صعوبات التعلم.

وفيما يتعلق بالسؤال المفتوح حول الحاجات التدريبية الأخرى المقترحة من قبل المعلمين فقد جاءت إجابات أفراد عينة البحث وفق الآتي:

• 83\% من أفراد العينة اقترحوا ايجاد سبل للتعاون بين جميع الأطراف لمساعدة التلاميذ ذوي صعوبات التعلم • 80\% من أفراد العينة اقترحوا إقامة فعاليات تهدف لتحسين التعاون بين التلاميذ، وتقبل بعضهم لبعض. • 73\% من أفراد العينة اقترحوا تدربب المعلمين على طرائق مساعدة الأطفال ذوي صعوبات التعلم. 2- نتائج فرضيات البحث: تم اختبار الفروض عند مستوى الالالة (0.05): الفرضية الأولى: لا توجد فروق ذات دالة إحصائية بين متوسطات إجابات المعلمين على استبانة البحث تعزى إلى متغير المؤهل العلمي. للتحقق من صحة هذه الفرضية قام الباحث بحساب الفروق بين متوسطات درجات المعلمين على استبانة البحث استتاداً إلى متغير المؤهل العلمي (معهد دبلوم أو ما يعادله، بكالوريوس (جامعي)، دراسات عليا)، وذلك باستخدام معامل تحليل التباين الأحادي، وجاءت النتائج كما وجاءت النتائج كما يوضحها جدول رقم (7):

الجدول (7) نتائج اختبار تحليل التباين الأحادي للفروق بين إجابات عينة البحث وفق متغير المؤهل التعليمي

\begin{tabular}{|c|c|c|c|c|c|}
\hline قيمة الاحتمال & قيمة ف & متوسط المربعات & درجة الحرية & مجموع المربعات & Anova اختبار \\
\hline
\end{tabular}




\begin{tabular}{|c|c|c|c|c|c|}
\hline \multirow{3}{*}{0.970} & \multirow{3}{*}{0.030} & 0.927 & 2 & 1.853 & بين المجموعات \\
\hline & & 30.927 & 77 & 2381.347 & داخل المجموعات \\
\hline & & & 79 & 2383.200 & المجموع \\
\hline
\end{tabular}

يتبين من الجدول رقم (7)، وبعد اختبار تحليل التباين (ANOVA) أن قيمة (ف) (0.030) وهي غير دالة إحصائياً. وبالتالي نقبل الفرضية الصفرية، أي لا توجد فروق ذات دالة إحصائية بين متوسطات إجابات المعلمين على استبانة البحث تعزى إلى متغير المؤهل العلمي.

ويمكن أن يفسر ذلك باتفاق معظم المعلمين على متطلبات التربية الفنية والحاجة لطوير واقع التربية الفنية لدعم الأطفال ذوي صعوبات التعلم، وهذا ما تؤكد عليه الكثير من الدراسات، ومنها دراسة (شبيطة وبصلات، 2015) إذ خلصت إلى ضرورة تدريب المعلمين على التعامل مع الأطفال ذوي صعوبات التعلم، وآلية دمجهم في المدارس، وتوفير المستلزمات المناسبة لذلك، وكذلك خلصت دراسة(سكروجز وبريغهام وماستروبيري، 2013) إلى ضرورة وضع المعايير للتعلم لما له من آثار ايجابية لاعم ذوي صعوبات التعلم.

الفرضية الثانية: لا توجد فروق ذات دالة إحصائية بين متوسطات إجابات المعلمين على استبانة البحث تعزى إلى متغير سنوات الخبرة في التدريس. للتحقق من صحة هذه الفرضية قام الباحث بحساب الفروق بين متوسطات درجات المعلمين على استبانة البحث تعزى إلى متغير سنوات الخبرة في التتريس (أقل من خمس سنوات، من خمس سنوات إلى أقل من عشر سنوات، من 10 إلى أقل من 15 سنة، 15 سنة فأكثر )، وذلك باستخدام معامل تحليل التباين الأحادي: وجاءت النتائج كما يوضحها جدول رقم (8):

الجدول (8) نتائج اختبار تحليل التباين الأحادي للفروق بين إجابات عينة البحث وفق متغير سنوات الخبرة في التدريس

\begin{tabular}{|c|c|c|c|c|c|}
\hline قيمة الاحتمال & قيمة ف & المربعات & درجة الحرية & المربعات & Anova اختبار \\
\hline \multirow{3}{*}{0.985} & \multirow{3}{*}{0.051} & 1.606 & 3 & 4.818 & بين المجموعات \\
\hline & & 31.294 & 76 & 2378.382 & داخل المجموعات \\
\hline & & & 79 & 2383.200 & المجموع \\
\hline
\end{tabular}

يتبين من الجدول رقم (8)، وبعد اختبار تحليل التباين (ANOVA) أن قيمة (ف) (0.051) وهي غير دالة إحصائياً. وبالتالي نقبل الفرضية الصفرية، أي لا توجد فروق ذات دالة إحصائية بين متوسطات إجابات المعلمين على استبانة البحث تعزى إلى متغير سنوات الخبرة في التدريس.

ويمكن أن يفسر ذلك باتفاق معظم المعلمين بمختلف خبراتهم التدريسة على متطلبات التربية الفنية والحاجة لتطوير واقع التربية الفنية لدعم الأطفال ذوي صعوبات التعلم، وتتفق هذه النتيجة مع دراسة (زهراني، 2010) التي بينت عدم وجود فروق تبعاً

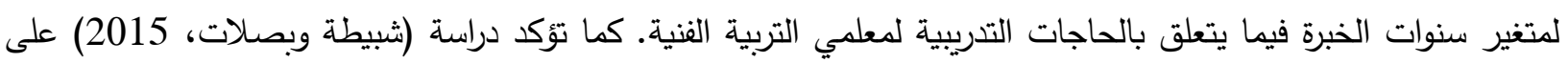


ضرورة تدريب المعلمين على التعامل مع الأطفال ذوي صعوبات التعلم، وآلية دمجه في المدارس، وتوفير المستلزمات المناسبة لدعم الأطفال ذوي صعوبات التعلم.

13 ـ مقترحات البحث:

- تضمين التربية الفنية بأهداف تراعي الأطفال ذوي صعوبات التعلم. - - تضدين محتوى مواد التربية الفنية بدروس تتمي قدرات الأطفال ذوي صعوبات التعلم. - - تدريب المعلمين على طرائق التعامل مع الأطفال ذوي صعوبات التعلم. - - مضع خطط فردية لمساعدة الأطفال ذوي صعوبات التعلم. - - إقامة أنشطة فنية لمجتمع المحلي يشارك فيها الأطفال ذوي صعوبات التعلم. - - توفير غرفة مصادر للتعلم .

- وضع خطة مشتركة بين جميع الأطراف في المدرسة بالتعاون مع الأهل لدعم الأطفال ذوي صعوبات التعلم. - قائمة المراجع:

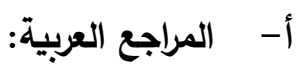

- إيواي، كاوري. (2002). أثر تعليم الفنون في حياة الطفل. (ترجمة أحمد عطية). مجلة مستقبليات. مجلد بr(2). .526-511 - بريطل، جورية . (2017). فاعلية برنامج تدريبي قائم على الفن التشكيلي لتأهيل أطفال التوحد. رسالة ماجستير غير منشورة. كلية العلوم الإنسانية والاجتماعية. جامعة قاصدي مرباح. الجزائر.

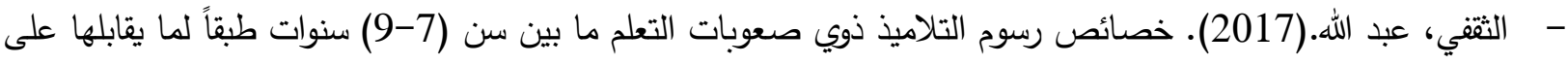
تقسيم فيكتور لونفيلد لمراحل نمو التعبير الفني عند الأطفال العاديين. مجلة التربية الخاصة. المجلد (5). العدد (18) ج2 يناير • 191-1927. جرادات، نادر والقبالي، يحيى.(2013). اتجاهات المعلمين نحو مشكلة صعوبات التعلم في المدارس الأساسية في الأردن. مجلة العلوم التربوية والنفسية، جامعة القصيم، السعودية، مجلد 7. 7. عدد 1. 481-515.

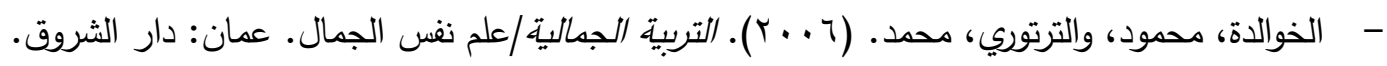

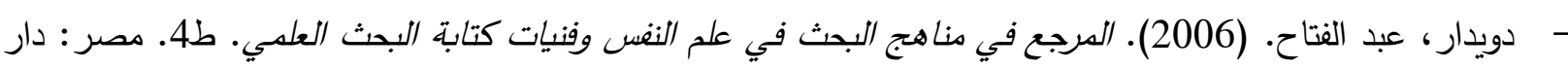
المعرفة الجامعية. - - الرزين، بدر بن عبد العزيز .(2015). برنامج علاجي مقترح في التربية الفنية لذوي صعوبات تعلم الرياضيات في

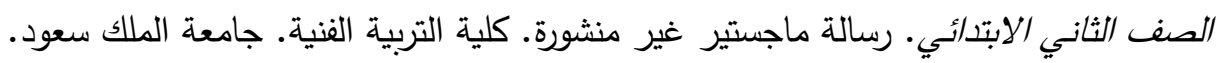

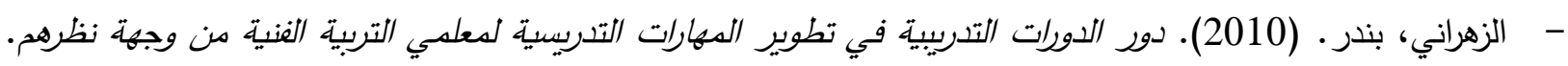
رسالة ماجستير غير منشورة، قسم التربية الفنية، كلية التربية، جامعة أم القرى، مكة المكرمة، السعودية.

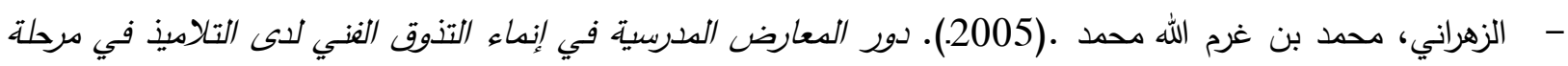
التعليم العام (المرحلة المتوسطة). رسالة ماجستير • جامعة أم القرى. كلية التربية.جدة. السعودية.

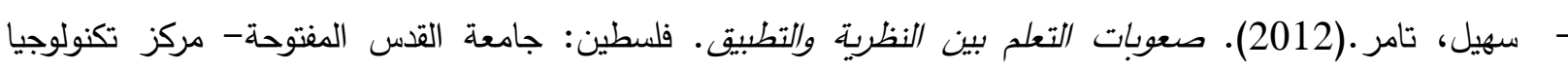
المعلومات والاتصالات. 


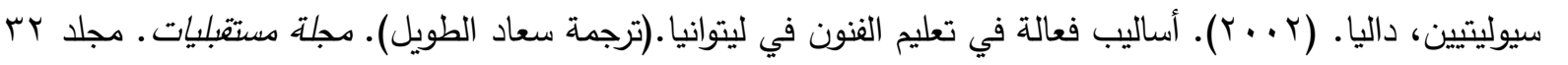
$.573-560 ،(2)$

شبيطة، مها وبصلات، نزار .(2015). دور برنامج التأهيل المجتمعي (CBR) في دمج الأطفال ذوي صعوبات التعلم في

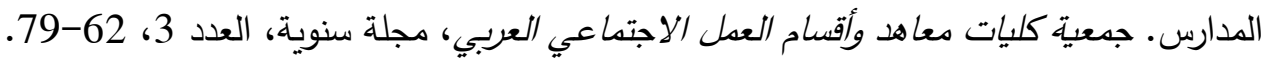

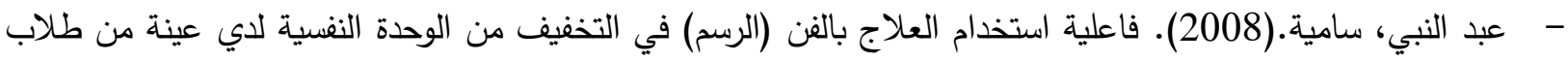

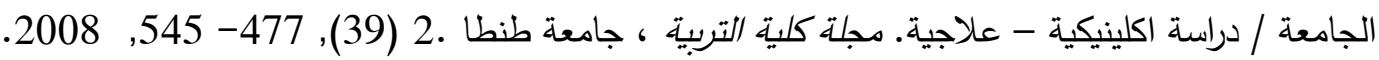
- - العجمي، لبنى.(2006). تغعيل برامج تقويم الأطفال ذوي صعوبات التعلم في ضوء خبرة الولايات الدتحدة الأمريكية. بحث مقدم للمؤتمر الدولي لصعوبات التعلم (نحو مستقبل مشرق) خلال الفترة 19-2006/12/22.

قرشم، أحمد و حسين، هثام.(2012). برنامج مقترح لعلاج صعوبات تعلم الرياضيات لدى تلاميذ المرحلة المتوسطة في مثئرون

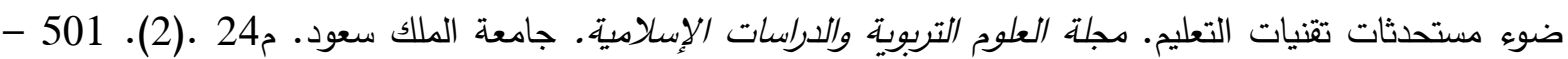

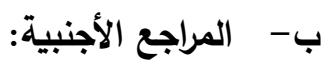

- Ahn, Park hyeri. (2003). Instructional Use of the Internet by high school art teachers in Missouri- PhD. University of Missouri - Columbia. DAl-a.

- Jensen, E . (2001). Arts with the Brain in Mind, Association for Supervision and Curriculum Development, Alexandria, VA.

- Keneth, E., Tommy, S. (1996). A survey of art Teachers Needs. School of Art \& Sculpting, 92(4), U.S.A.

- Luehrman, mick. (2003). Art Experiencies and Attitudess twards art Education: adescriptive study of Missouri public school principals. Studies in Art Education, volume 43, issue3; National Art Association, teston.

- Pifalo, T. (2006): Art Therapy with Sexually Abused Children and Adolescents: Extended Research Study, Art Therapy: Journal of the American Art Therapy Association, V23 N(4), $181-185$.

- Saldana, Claudia.(2016).Children with Disabilities: Constructing Metaphors and Meanings through Art. International Journal of Special Education. v31. n1.p88-96.

- Scruggs, Thomas E.; Brigham, Frederick J.; Mastropieri, Margo A.(2013). Common Core Science Standards: Implications for Students with Learning Disabilities. Learning Disabilities Research \& Practice. v28 .n1 .p49-57.

- Stelzer, F., Singer, P., John, P. and Chemtob, C. (2007): Art Therapy for Adolescents with Posttraumatic Stress Disorder Symptoms: A Pilot Study, Art Therapy: Journal of The American Art Therapy Association, V24 N(4), P. 163 - 169. 